\title{
MASTER
}

\section{An Arc-Discharge System for Nondestructive Detection of Flaws in Thin Ceramic Coatings}
G. W. Scott
E. V. Davis 


\section{DISCLAIMER}

This report was prepared as an account of work sponsored by an agency of the United States Government. Neither the United States Government nor any agency Thereof, nor any of their employees, makes any warranty, express or implied, or assumes any legal liability or responsibility for the accuracy, completeness, or usefulness of any information, apparatus, product, or process disclosed, or represents that its use would not infringe privately owned rights. Reference herein to any specific commercial product, process, or service by trade name, trademark, manufacturer, or otherwise does not necessarily constitute or imply its endorsement, recommendation, or favoring by the United States Government or any agency thereof. The views and opinions of authors expressed herein do not necessarily state or reflect those of the United States Government or any agency thereof. 


\section{DISCLAIMER}

Portions of this document may be illegible in electronic image products. Images are produced from the best available original document. 


\section{Printed in the United States of America. Available from National Technical Information Service \\ U.S. Department of Commerce 5285 Port Royal Road, Springfield, Virginia 22161 \\ Price: Printed Copy $\$ 4.50$; Microfiche $\$ 3.00$}

This report was prepared as an account of work sponsored by an agency of the United States Government. Neither the United States Government nor any agency thereof, nor any of their employees, contractors, subcontractors, or their employees, makes any warranty, express or implied, nor assumes any legal liability or responsibility for any third party's use or the results of such use of any information, apparatus, product or process disclosed in this report, nor represents that its use by such third party would not infringe privately owned rights. 
Contract No. W-7405-eng-26

METALS AND CERAMICS DIVISION

h.

AN ARC-DISCHARGE SYSTEM FOR NONDESTRUCTIVE DETECTION OF FLAWS IN THIN CERAMIC COATINGS

G. W. Scott and E. V. Davis

Date Published: Apri! 1978 NOTISE

MN ONLY

PORTIONS OF THIS PEPORT ARE ILLEGHBLE. It

has bech remrof:ced from the best available copy yo permit the broadest possible avaitability.

OAK RIDGE NATIONAL LABORATORY

Oak Ridge, Tennessee 37830 operated by UNION CARBIDE CORPORATION for the DEPARTMENT OF ENERGY This report was prepared as an account of work
sponsored by the United States Government. Neither the
United States not the United States Department of
Energi, nor any of their employees, nor any of their
contractors, subcontractors, or their employets, makes
any wasratity, express or implited, or assumes any legal
liability or responsibility for the accuracy, completeress
of usefulness of any information, apparatus, product or
process disclosed, or represents that its use would not
infringe privately owned rights. 
THIS PAGE

WAS INTENTIONALLY

LEFT BLANK 
CONTENTS

ABSTRACT . . . . . . . . . . . . . . . . . . . 1

INTRODUCTION . . . . . . . . . . . . . . . . . . . 1

THEORY . . . . . . . . . . . . . . . . . . 2

Electrical Breakdown and Discharge . . . . . . . . . 2

Electrical Model of the Discharge Probe Before Discharge . . 5

EXPERIMENTAL WORK . . . . . . . . . . . . . . . . . 9

Equipment . . . . . . . . . . . . . . . . . . 9

Specimens . . . . . . . . . . . . . . 13

Procedures ..................... . 14

RESULTS AND DISCUSSION . . . . . . . . . . . . . . . 16

Analog Arc Current Measurements . . . . . . . . . 16

Exper1mental Observations . . . . . . . . . . . . . 19

Plan View Recording . . . . . . . . . . . . . . 21

CONCLUSIONS . . . . . . . . . . . . . . . . . . . 24

Applications . . . . . . . . . . . . . . 26

Future Work . . . . . . . . . . . . . . 27

ACKNOWLEDGMENTS . . . . . . . . . . . . . . . . . . 27

APPENDIX . . . . . . . . . . . . . . . . . . 29

SCAN AND RECORDING CONTROLLER. . . . . . . . . . . . . 30

Functions . . . . . . . . . . . . . . . . . 30

Circult Description and Operations - See Fig. A1 . . . . . 30

$X$ - and $Y$-axis Position . . . . . . . . . . . 30

Dat.a potentiometer power . . . . . . . . . . . 30

Pen control .................... 32 
AN ARC-DISCHARGE SYSTEM FOR NONDESTRUCTIVE DETECTION OF FLAWS IN THIN CERAMIC COATINGS

G. W. Scott and E. V. Davis

\begin{abstract}
The feasibility of nondestructively detecting small cracks or holes in plasma-sprayed ceramic coatings with an electric arc-discharge system was studied. We inspected $\mathrm{ZrO}_{2}$ coatings $0.46 \mathrm{~mm}$ ( $0.018 \mathrm{in.})$ thick on Incoloy alloy 800 substrates. Cracks were artificially induced in controlled areas of the specimens by straining the substrates in tension. We designed and built a system to scan the specimen's surface at approximately $50 \mu \mathrm{m}$ (0.002 in.) clearance with a sharppointed metal-tipped probe at high dc potential. "The system measures the arc currents occurring at flaws, or. plots a map of the scanned area showing points where the arc current exceeds a preset threshold. A theoretical model of the probe-specimen circuit shows constant dc potential to be the best choice for arc-discharge inspection of insulating coatings. Experimental observations and analysis of the data disclosed some potential for flaw description.
\end{abstract}

\title{
INTRODUCTION
}

We have determined the feasibility of nondestructively detecting small cracks or holes in plasma-sprayed ceramic coatings with an electric arc-discharge system. Our prototype system can indicate the lncation of a defect response and provide a rough map of the defect indications in a given area.

Thin ceramic coatings, nominally $0.25 \mathrm{~mm}$ ( $0.010 \mathrm{in.})$ thick, are being evaluated for application to internal parts of equipment used to process or burn coal. The hostile operating environment inside such equipment dictates the use of highly protective material systems to reduce the rates of corrosive and erosive attack. A number of metal oxides and other materials are under study. We chose plasma-sprayed zirconia $\left(\mathrm{ZrO}_{2}\right)$ as a "typical" test material for the investigation of nondestructive inspection methods.

Plasma-sprayed coatings are generally porous and have a rough, uneven surface. The ceramics are also hard, which makes the coating 
layer highly abrasive to materials in sliding contact with it. Therefore, minimum contact by inspection-device probes is highly desirable.

Electric discharge methods have been extensively used in a few specific areas, for example, the testing of electrical cable insulation ${ }^{1}$ and certain items of weapon or aerospace hardware. ${ }^{2}$ These methods have measured the effects of discharges occurring in confined voids within dielectric material layers. "Open air" discharge methods have been limited to simple continuity tests of paint films or other metal coatings with so-called "holiday" (uncovered area) detectors. ("Holiday" derives from nautical slang usage, meaning an area missed when a surface is painted.)

The present work is an application of the "open-air" discharge method. We have added a recording system to map an area of the inspected surface and display an image of flaws whose responses exceed a preset. threshold. We have also made some measurements of arc current and related them to defect structure.

\section{THEORY}

To appreciate the electrical measurement and control problems associated with an electrical discharge system, one must first understand the phenomena of breakdown and discharge, and then consider models to describe the behavior of the probe-specimen circuit.

\section{Electrical Breakdown and Discharge}

There has been extensive research on electrical discharges, both theoretical and experimental. Jones ${ }^{3}$ and Loeb $^{4}$ summarize the earlier work well and provide phenomenological descriptions, which are excellent for the present purpose.

\footnotetext{
${ }^{1}$ F. H. Gooding and H. B. Slade, "Corona Level Scanning of High Voltage Power Cables," Trans. AIEE 76: 999-1006 (1957):

${ }^{2} \mathrm{~J}$. A. Hendron et a1., "Corona and Microwave Methods for the Detection of Voids in Glass-Epoxy Structures," Mater. Eval. 22(7): 311-314 (1964).

${ }^{3} \mathrm{~F}$. Llewellyn Jones, "Ionization Growth and Breakdown," in Encyclopedia of Physics, Springer-Verlag, Berlin, 1956, Chap. 22, pp. 1-52.

${ }^{4}$ L. B. Loeb, "Electrical Breakdown of Gases with Steady or Direct Current Impulse Potentials," in Encyclopedia of Physics, Springer-Verlag, Berlin, 1956, Chap. 22, pp. 445-530.
} 
Some clartfication of definitions will help describe what occurs in the testing situation. "Breakdown" denotes the condition in which electron current across a gap just becomes self-sustaining. The current will be of the order of $1 \mathrm{pA}$ (for spherical or needle electrodes) and its flow is not accompanied by observable light, heat, or noise. "Discharge" preceded by a modifier such as "corona," "glow," or "arc" describes the type of conduction current mechanism. "Spark breakdown" is a transient phenomenon, such as occurs between a glow and an arc, in which the current increases suddenly and irreversibly.

Breakdowns occur by an avalanche process. An electron at the cathode is accelerated toward the anode; each time it acquires sufficient energy it may collide with a gas atom and ionize it, releasing additional electrons. The electron swarm thus generated grows exponentially, so that for one electron starting at the cathode, $e^{\alpha d}$ electrons arrive at the anode, a distance $d$ away. The probability that the initial electron will release one additional electron per unit of distance traveled is $\alpha$. If the discharge is to sustain itself, at least one new electron must be released near the cathode for each avalanche that occurs. Possible mechanisms for release include positive ions or photons striking the cathode or other gas atoms; these are secondary processes, which do not count as part of the avalanche. If each electron released in the avalanche has a probability, $\gamma$, of releasing another electron by a secondary process, then the condition for a sustained discharge is

$$
\gamma\left(e^{\alpha d}-1\right)=1
$$

This is the so-called "Townsend condition;" $\alpha$ and $\gamma$ are called the first and second Townsend ionization coefficients. The so-called "Townsend breakdown" is the very low.current, self-sustaining discharge described above.

Spark breakdown occurs at much larger currents than the Townsend breakdown and also includes large increases in current. Sparks are produced by a different avalanche mechanism than the Townsend breakdown. In more intense electric fields, the accelerating electrons produce 
significant ionization by excitation or ejection of inner-shell electrons, and the photons produced by electronic energy-loss transitions precede the electron-ionization front, producing additional ionfzation further across the gap. The photon action forms a so-called "streamer," which is a rapidly traveling column of ionized gas. The arrival of the streamer at the anode is followed limediately by a return stroke from anode to cathode. The addition of the photon velocity to the ordinary electron drift velocity causes the streamer velocity to be much higher than the collision-type avalanche velocity.

For the conditions realized in experiments described by Jones ${ }^{3}$ and Loeb ${ }^{4}$ including gases and electrodes of uncontrolled purity and cleanliness, breakdown voltages for uniform fields follow a Paschen relation, ${ }^{5}$ in which the voltages vary as a function of $p d$, the product of pressure (or density) and distance (between electrodes). The relation for air and many other gases has a $p d$-value, $(p d)_{m}$; where a minimum breakdown voltage occurs. At this voltage, the energy of accelerated electrons is used. most efficiently in collision ionization processes. For $p d<(p d)_{m}$, gas atoms are sparse, collisons are fewer, and electrons deposit energy on the anode as heat. For $p d \vec{d}(p \dot{d})_{m}$, electron energy is dissipated in collisions with gas atoms, but many of the electrons produced are lost (e.g., by recombination) before reaching the anode.

The net result of various controlling mechanisms is a decrease in breakdown field requirements with increasing gap at atmospheric pressure in air. Published data ${ }^{5}$ show that for flat, parallel electrodes, the field required to break down a $0.5-\mathrm{mm}(0.020-\mathrm{in}$.) air gap at atmospheric pressure is about $50 \%$ of that required to break down a $0.05-\mathrm{mm}(0.002-\mathrm{in.}$ ) gap. (Note that the field is proportional to the voltage divided by the distance between electrode surfaces.) It has also been shown that dielectric materials function as well as metals for electrodes ${ }^{6}$ for equal field intensities.

${ }^{5}$ T. W. Dakin, "Insulating Gases," pp. 4-135-4-143 in D. G. Fink and J. M. Carroll, eds., Standard Handbook for Electrical Engineers, 10th ed., McGraw-Hill, New York, 1968.

${ }^{6}$ H. C. Hall and R. M. Russek, "Discharge Inception and Extinction in Dielectric Voids," Proc. Inst. Elec. Eng. Part 2: 101, 47-55 (1954). 
Electrical Model of the Discharge Probe Before Breakdown

This study used point-to-plane discharge gap geometry; the plane was covered with a dielectric layer, which filled most of the gap. Figure 1 shows two configurations; a sound coating and a coating with a defect. The major effects can be fllustrated with the pointed electrode replaced by a parallel plate, thus avoiding a display of complex field calculations. The resulting configuration is the so-called Maxwe11-Wagner two-layered capacitor. ${ }^{7}$

The permittivity of air, $\varepsilon_{1}$, can be assumed equal to $\varepsilon_{0}$, the vacuum value $(8.854 \mathrm{pF} / \mathrm{m})$. The permittivity of the coating is $\kappa_{2} \varepsilon_{0}$, where $\kappa_{2}$ is the dielectric constant of the coating. The coating layer with the defect has the same air layer as the sound coating plus an air column of area $B A$, where $A$ is an effective area for the probe and $B$ is a constant. The corresponding ceramic area is then $(1-\beta) \dot{A}$.

The following analysis corresponds to conditions preceding the onset of discharge. General expressions will be specialized to the case for an applied dc voltage, and transients related to the scanning motion of the probe will be ignored. The parallel-plate model is useful in describing circuit behavior because the effects of the asymetric field can be absorbed in the geometric constants $A, \beta, \delta$, and $d$, replacing actual by effective values.

Consider first a parallel-plate capacitor with no dielectric. The electrical constants are:

$$
R_{0}=\frac{\rho_{1} d}{A}, C_{0}=\frac{\varepsilon_{0} A}{d} \text {, and } \tau_{0}=R_{0} C_{0}=\rho_{1} \varepsilon_{0}
$$

Here and in what follows, $R$ denotes resistance, $C$ denotes capacitance, $\tau$ denotes a time constant ( $R C$-product) and $Z$ denotes an impedance. For an applied potential (voltage) $V$, the electric field in the gap will be

$$
E_{0}=V / d
$$

${ }^{7}$ A. von H1ppel, "Dielectrics," Part 4, Khap. 7; pp. 4-102-4-128 in Handbook of Physics, E. U. Condon and H. Odishaw (eds.), McGraw-Hill, New York, 1967. 


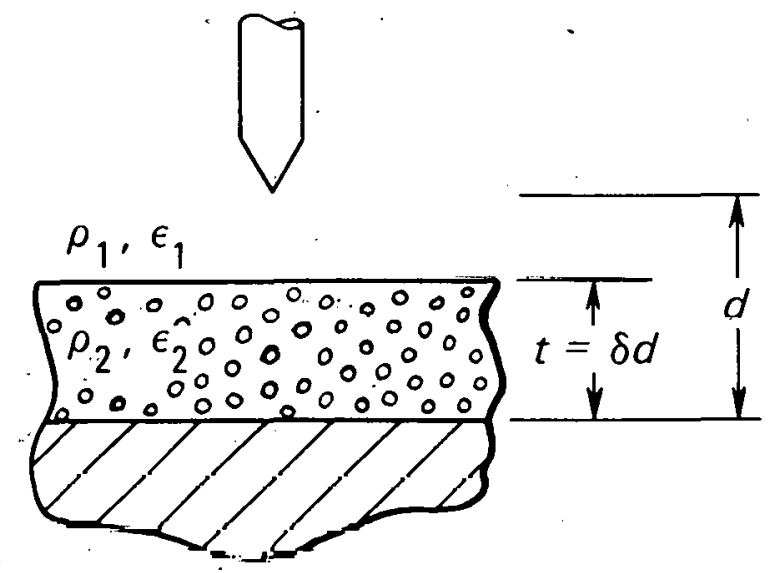

ORNL-DWG 78-76

SOUND COATING

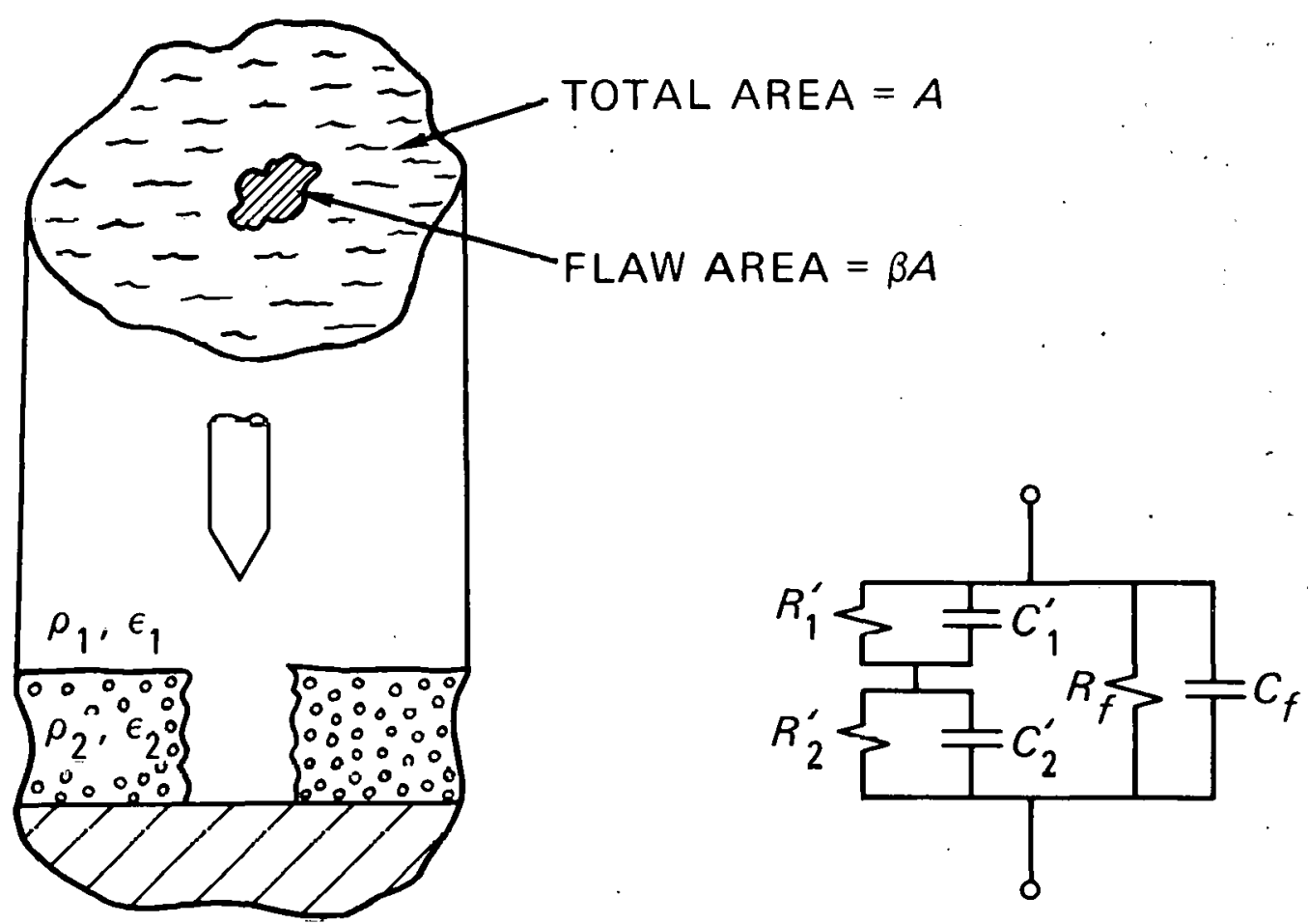

\section{FLAWED COATING}

Fig. 1. Physical and Electrical Schematics of the Probe-Specimen Circuits for Sound and Flawed Coatings. Here, $\varepsilon_{1}$ and $\varepsilon_{2}$ are the permittivities of the air and dielectric layer, respectively; $\rho_{1}$ and $\rho_{2}$ are the resistivities; $d$ is the total gap between the probe and the underlying metal substrate; $t$ is the coating (dielectric) thickness; and $\delta$ is the effective fraction of the gap occupied by the coating. 
For the air gap above a sound coating layer [thickness $(1-\delta) d$ ],

$$
\begin{aligned}
& R_{1}=\frac{\rho_{1}(1-\delta) d}{A}=(1-\delta) R_{0} \\
& C_{1}=\varepsilon_{0} A /(1-\delta) d=C_{0} /(1-\delta) .
\end{aligned}
$$

The impedance is the parallel combination for $R_{1}$ and $C_{1}$ :

$$
z_{1}=\frac{R_{1}}{1+j \omega \tau_{1}}=\frac{(1-\delta) R_{0}}{1+j \omega \tau_{0}}
$$

where $\omega=$ the applied frequency and $\tau_{1}=\tau_{0}$. For the coating layer itself (thickness $t=\delta d$ )

$$
R_{2}=\rho_{2} \delta d / A=\rho \delta R_{0}
$$

where $\rho=\rho_{2} / \rho_{1}$,

$$
C_{2}=\varepsilon_{2} A / \delta d=\kappa_{2} C_{0} / \delta
$$

and

$$
Z_{2}=R_{2} /\left(1+j \omega \tau_{2}\right)
$$

The total impedance is the sum

$$
Z_{T}=Z_{1}+Z_{2}=\frac{R_{1}}{1+j \omega \tau_{1}}+\frac{R_{2}}{1+j \omega \tau_{2}} .
$$

For the special case of direct current (dc),

$$
Z_{T}(\omega=0)=R_{1}+R_{2}
$$

Conclnuity of current density requires that the electric fields in the air gap and coating layer be related by

$$
\frac{E_{2}}{\vec{E}_{1}}=\frac{\rho_{2}}{\rho_{1}}=\rho
$$

The more resistive 1 ayer will sustain the higher electric ficld intensity. 
Comparison of the fields with and without the coating shows the effect of inserting it. The sum of the voltage drops across the layers equals the total applied voltage, so

$$
V=E_{1}(1-\delta) d+E_{2} \delta d
$$

Substituting Eqs. (8) and (3) yields

and

$$
E_{1}=\frac{V}{[(1-\delta)+\rho \delta] d}=\frac{E_{0}}{1-\delta+\rho \delta}
$$

$$
E_{2}=\rho E_{0} /(1-\delta+\rho \delta)
$$

If $\rho_{2}>\rho_{1}(\rho>1)$, the field across the coating $\left(E_{2}\right)$ will be greater than $E_{0}$, and the field across the remaining air gap $\left(E_{1}\right)$ will be less than $E_{0}$. The atmosphere of the open-air test contains air and water vapor, and it is exposed to light and other ionizing background radiation. Therefore the avallability and mobility of charges in the gap should exceed that of the coating, yielding a value of $\rho$ greater than unity. If the air gap is in a breakdown condition, its conductivity will be significantly larger than that of the dielectric.

If one starts from Eq. (6) for the alternating current (ac) case, condition ( 8 ) must be replaced by a continuity equation for the electric field. The result is that, for ac or suddenly applied dc potentials, the higher field occurs across the medium with the lower dielectric constant, that is, the air gap. Therefore, constant-potential dc is the correct voltage choice for testing the integrity of a dielectric coating layer.

The analysis for the flaw condition proceeds along the same lines followed above. For a perfect paralle1-plate capacitor, any fringing fields near the defect can be ignored, so electrical values for the flaw are 


$$
\begin{aligned}
& R_{f}=\rho_{1} / d B A=R_{0} / \beta \\
& C_{f}=\frac{\varepsilon_{0} \beta A}{d}=B C_{0},
\end{aligned}
$$

and

$$
z_{f}=\frac{R_{f}}{1+j \omega \tau_{f}}=\frac{R_{0}}{\alpha\left(1+j \omega \tau_{0}\right)} .
$$

The altered impedances over the coated area, shown primed in Fig. I, can also be computed by correcting earlier equations with $\beta$, if transient analysis is desired. The important characteristic of the flaw is that the field there w1ll be the same as that for an air-filled capacitor [Eq. (3) ] .

\section{EXPERIMENTAL WORK}

Basic objectives of the experiments were to: (1) develop the ability to detect the presence of an arc discharge with electrical instruments, (2) measure the arc current, (3) record the arc current and the location of the current measurement in a useful way, and (4) show a correlation between arc current measurements and known flaws in a workpiece or specimen. Secondary objectives included: (1) optimizing the resolution of the system, (2) reducing the rate of probe electrode burnup, (3) developing practical ways to support the specimen and scan the probe over it.

\section{Equipment}

Figure 2 shows the functional design and construction of the system. It can be divided into four subsystems: (1) the probe electrical system, (2) arc-current and probe-voltage measuring equipment, (3) the probc support and scanning mechanism, and (4) data recording and display.

The probe electrical supply is continuously adjustable, 0 to $30 \mathrm{kV}$ with maximum $2 \mathrm{~mA}$ current capacity, connected to provide a positive voltage with respect to ground. Six 10-M resistors provide a constant leakage path to ground and a measuring leg for the applied voltage. The $30-M \Omega$ resistor in series with the probe limits the arc current. The 


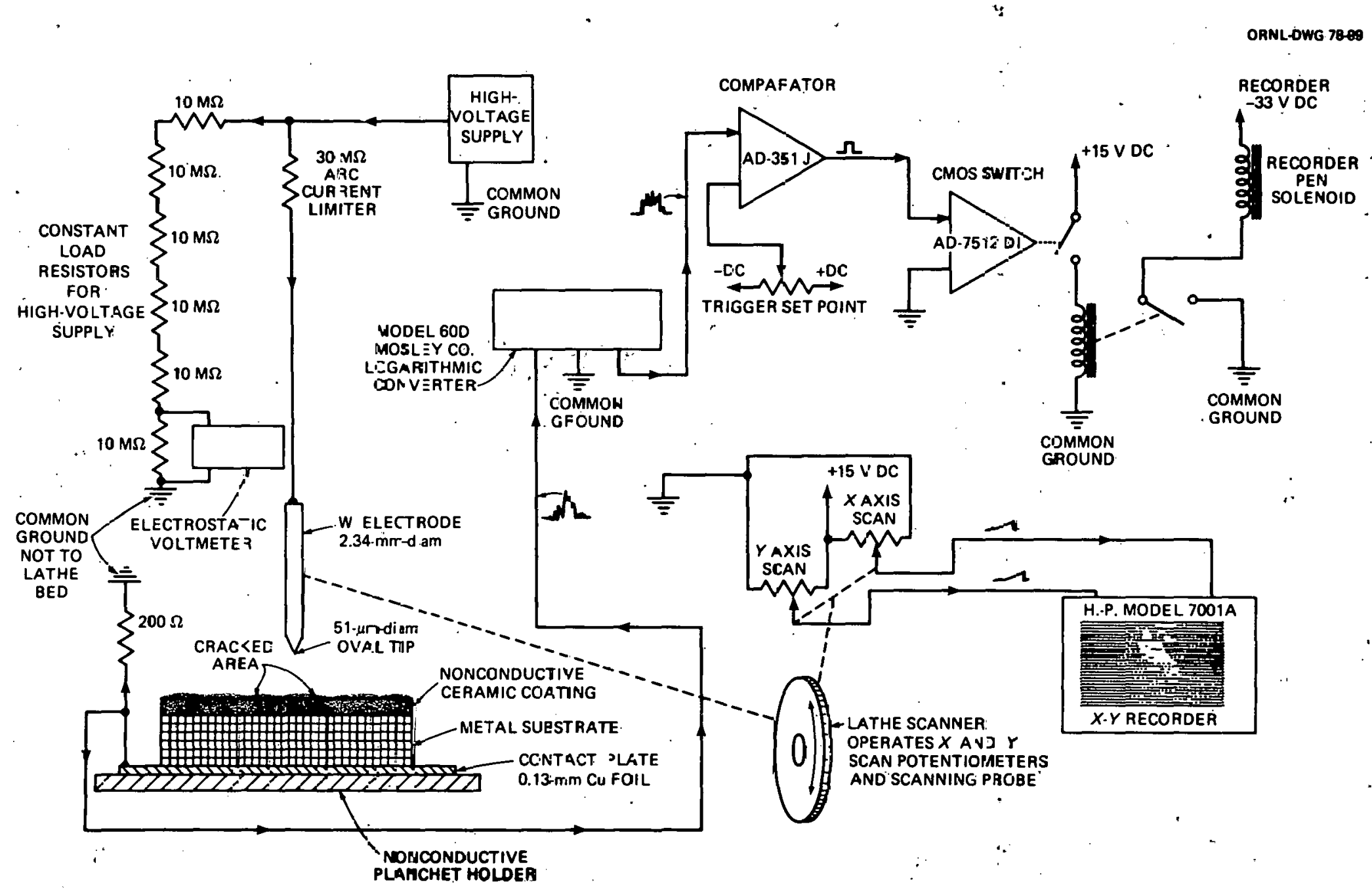

Fig. 2. Fuxctional Schematic of the Arc Discharge Scanning System. 
arc-current signal develops across the $200-\Omega$ resistor between the specimen contact plate (copper foil) and ground.

The probe is a 2.3-mm-diam (0.092-in.) tungsten rod. Its tip is ground in a $30^{\circ}$ cone, which terminates in a segment of a sphere of 0.05 to $0.08 \mathrm{~mm}$ ( 0.002 to $0.003 \mathrm{in.})$ diameter. The rod is held in a cylindrical Teflon mount (see Fig. 3). This probe design evolved from a number of trials and provides the best resolution and burnout resistance.

Probe voltage is measured by the electrostatic voltmeter across the bottom resistor in the $60-\mathrm{M} \Omega$ string. The voltage division has not been precisely calibrated, but the absolute voltage can be estimated as 6 times the meter reading, and the system can be reset with a voltage repeatable to within less than $1 \%$.

To measure the arc current, the voltage across the 200- $\Omega$ resistor is fed into the Moseley logarithmic converter. For inputs between $1 \mathrm{mV}$ and $1 \mathrm{~V}$, the converter produces an output from approximately zero to $-60 \mathrm{mV}$, $-1 \mathrm{mV} / \mathrm{db}$ over a $60-\mathrm{db}$ range. Logarithmic conversion is very helpful in differentiating levels of arc current, because the current varies rapidly over a few orders of magnitude as a flaw is scanned.

Figure 3 shows the mechanical parts of the probe support and scanner. The tailstock of the surplus lathe bed was removed to provide a space on the ways for the insulated specimen platform and the contact plate. A salvaged microscope focusing mechanism mounted on the tool table provides vertical motion, which is measured with a dial indicator. Motion parallel to the ways ( $X$ direction), is provided by the tool table drive (lead screw). The manual tool cross-feed provides $Y$-motion.

Data recording and display evolved through several steps to the current method. Early efforts used a strip chart or $X-Y$ recorder plot of arc current ( $Y$-axis) vs position ( $X$-axis) along a single line scan the length of the specimen. Later, we added data potentiometers to the lathe-scanner axes and built the scan and recording controller, which is described in more detail in the Appendix. The controller transmits position information to the $X$ and $Y$ axes of the recorder. It compares the output from the logarithmic converter with a reference voltage and generates a signal to raise or lower the recorder pen. Adjustment of the reference voltage provides a threshold for the recording. 


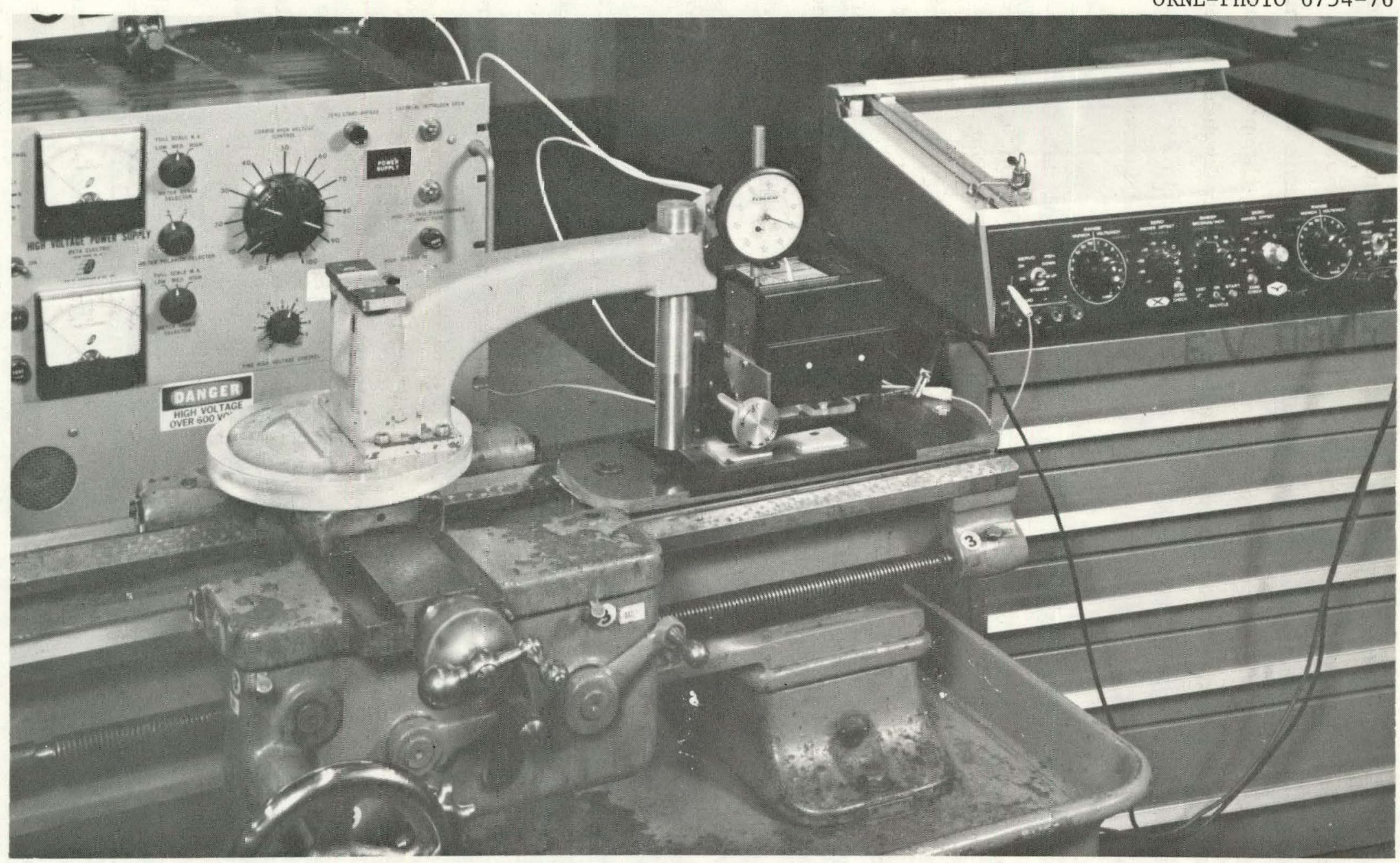

Fig. 3. The Arc Discharge Scanning Mechanisn. 
The recording thus produced contains an enlarged plan view of the scanned area of the specimen plus binary information about the arc current level at each scanned point. The "positive" mode causes the pen to write an ink line wherever the arc current exceeds the preset threshold value. The "negative" mode causes the pen to write everywhere except where the arc current exceeds the threshold.

\section{Sperimens}

The specimen used for this work contained artifically induced cracks in a $\mathrm{ZrO}_{2}$ coating $0.46 \mathrm{~mm}$ (0.018 in.) thick. The specimen type was designed for use in development of surface inspection methods. ${ }^{8}$ Figure 4 shows the present design; earlier specimens, including the one used here, were completely coated on one side. Pulling the coated specimen in a tensile-testing machine produced the cracks in the throat (necked-down) area of the specimens.

${ }^{8}$ S. D. Synder, "Liquid Penetrant Testing," Coal Technology Program Quart. Prog. Rep. Sept. 30, 1976, ORNL-5224, pp. 64-68.

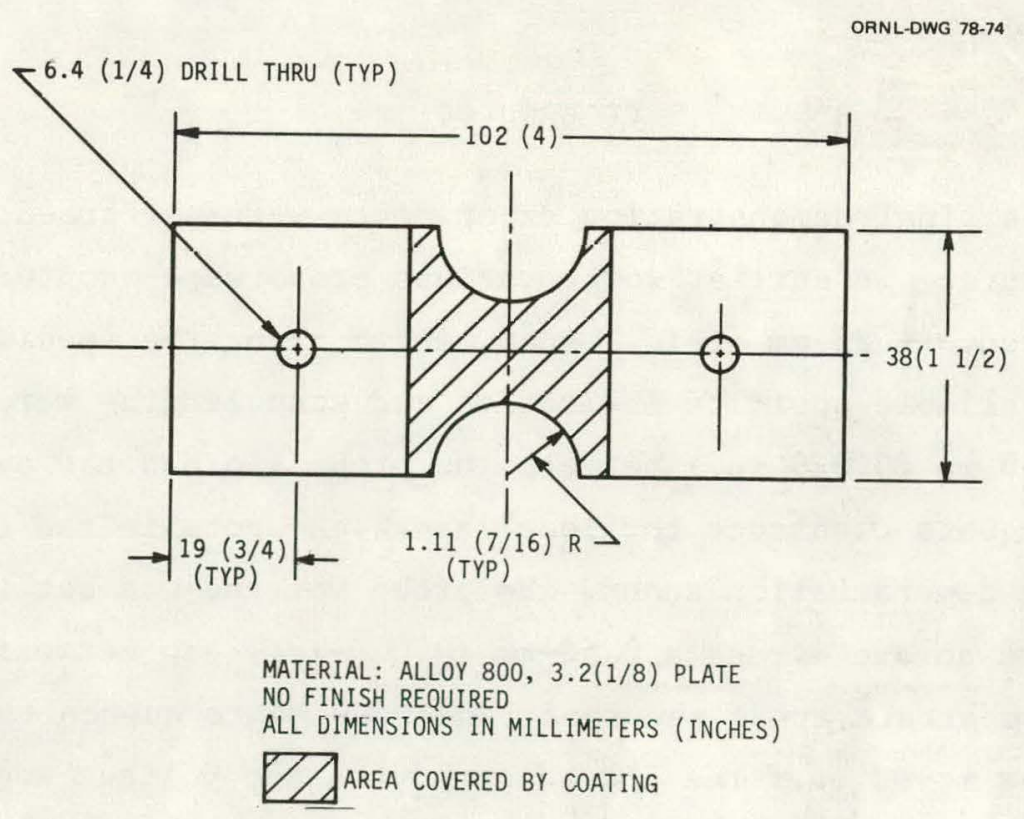

Fig. 4. Design of Tensile-Crack Specimen. 
The presence of cracks in the specimen has been verified by visual inspection and filtered particle inspection. Visual inspection ${ }^{8}$ (Fig. 5) disclosed a major system of three or four fissures. Filtered particle inspection $^{8}$ (Fig. 6) showed a more complex crack pattern.

The filtered particle method uses a liquid suspension of flourescent dye particles having a controlled size range. When this suspension is dropped on a surface, the liquid vehicle preferentially soaks into cracks, leaving a collection of particles around the edge of the crack to produce an indication. It appears likely that cracks that have opened to the surface and reclnser ronld produce filtered particle indications while remaining undetectable visually.

Two aspects of the crack structure that were not verifiable in this study are orientation and depth. We made transmission radiographs with the film placed next to the coated surface and observed some crack indications that correlate with the filtered particle indications. Although there are differences in the size and film density of the indications, it is difficult to distinguish slight differences in crack width from differences in depth. Detailed work with a microdensitometer to resolve the uncertainties was considered beyond the scope of this study.

\section{Procedures}

Only the final demonstration experiments were performed with a fixed procedure. In earlier work, various steps were adopted as they were optimized. A 25-mm (1-in.) scan length along the specimen was used as soon as reliable position indication and scan lengths were established. A gap of $0.50 \mathrm{~mm}(0.020 \mathrm{in}$.) between the probe tip and the substrate provided adequate clearance for localized high spots in the coating.

For the demonstration scans, the probe voltage was set to a level that produced an arc across a $0.50-\mathrm{mm}(0.020-\mathrm{in}$.) gap between the probe and a bare substrate area, recorded, and reduced to quench the arc. Then the probe was moved over the coated area, and the voltage was set to a level slightly above that required to produce the arc in air. The final settings were slightly above $3400 \mathrm{~V}$ for all the scans and varied slightly between scans. 

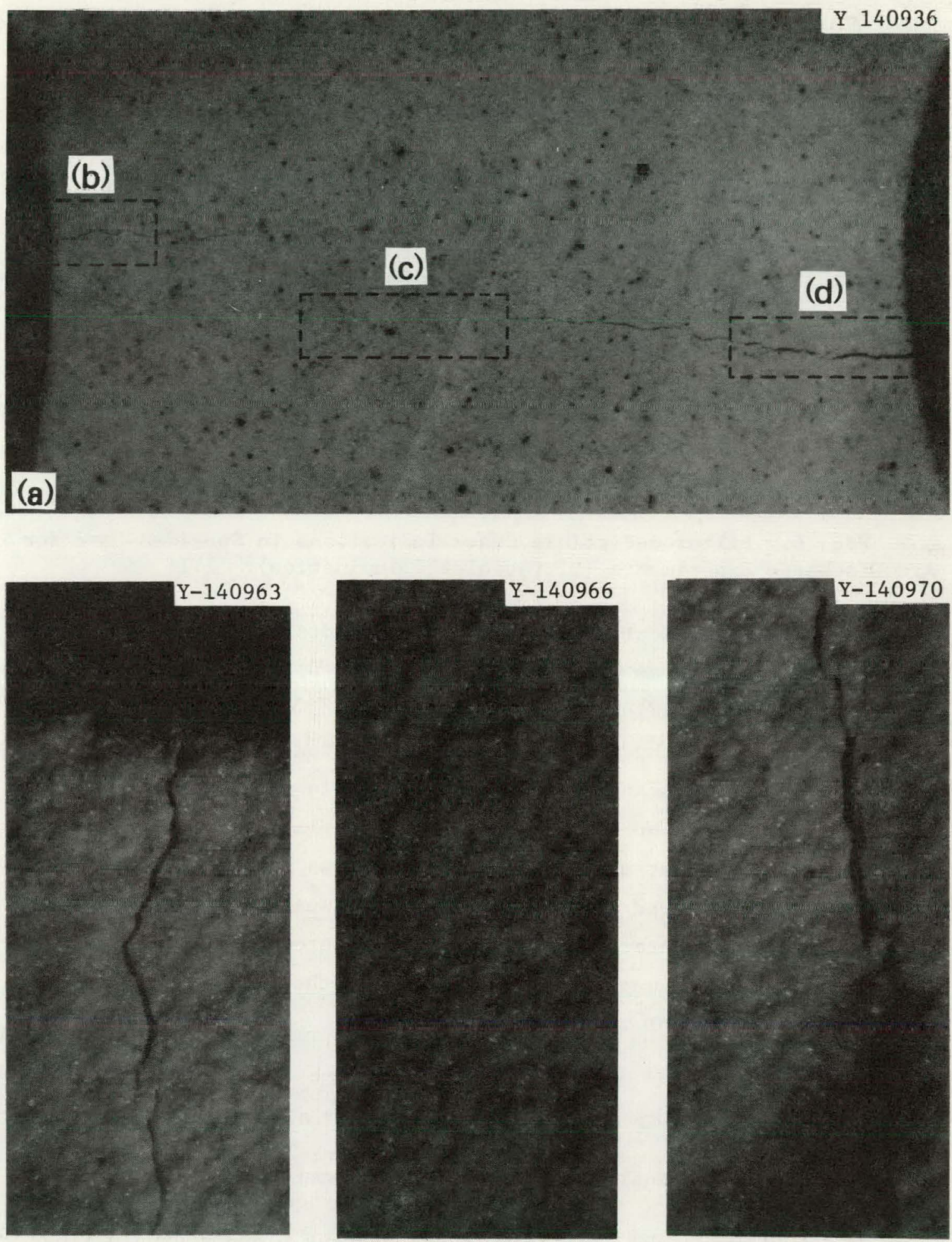

Fig. 5. Major Crack System in Specimen Used for Arc Discharge Experiments. (a) View across cracked area, $8.5 \times$. (b), (c), (d) Areas marked in (a) at $40 \times$. 


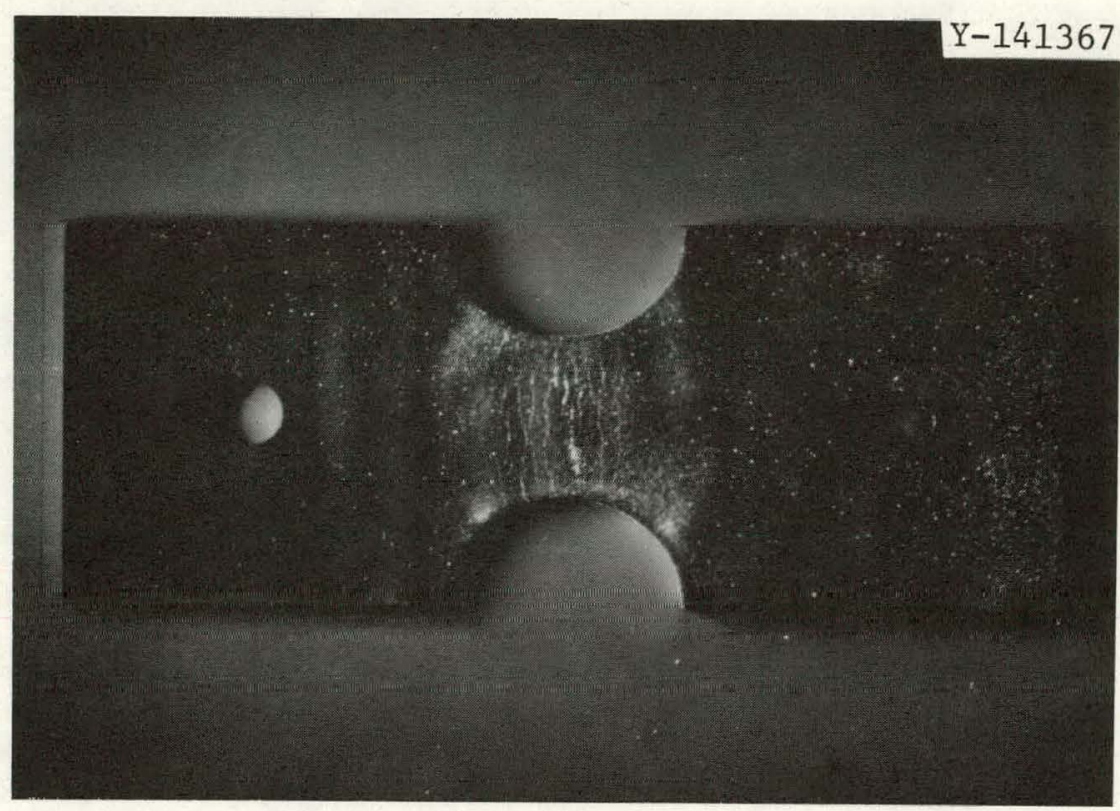

Fig. 6. Filtered-Particle Crack Indications in Specimen Used for Arc Discharge Experiments (Ultraviolet Illumination). 1.1x.

The axis magnifications were adjusted to display a scanned area of the specimen $19 \times 25 \mathrm{~mm}(0.75 \times 1.00$ in. $)$ on a $0.25 \times 0.38 \mathrm{~m}(10 \times 15$ in. $)$ paper chart. The $X$-axis, $25 \mathrm{~mm}$ on the specimen, was thus magnified about $15 \%$ more than the $Y$-axis. When raster scans of the full $19 \times 25 \mathrm{~mm}$ area were made, the scan lines were separated in the $Y$ direction by $0.32 \mathrm{~mm}$ (U.U125 in.) on the specimen. (F'or earlier single-line scans, the intervals were larger.) The $X$ direction was scanned from the head end toward the tail end of the lathe bed. Between scans, the tool rest was returned to its starting position and the cross-feed was indexed; the recorder pen was mechanically lifted, and the pen carriage followed the motion of the tool rest.

\section{RESULTS AND DISCUSSION}

\section{Analog Arc Current Measurements}

Figure 7 shows the variation in arc current along a single line scan the length of the scanner travel [25 mm (1 in.)] on the centerline of the specimen. The amplitude of the arc current was not calibrated, 


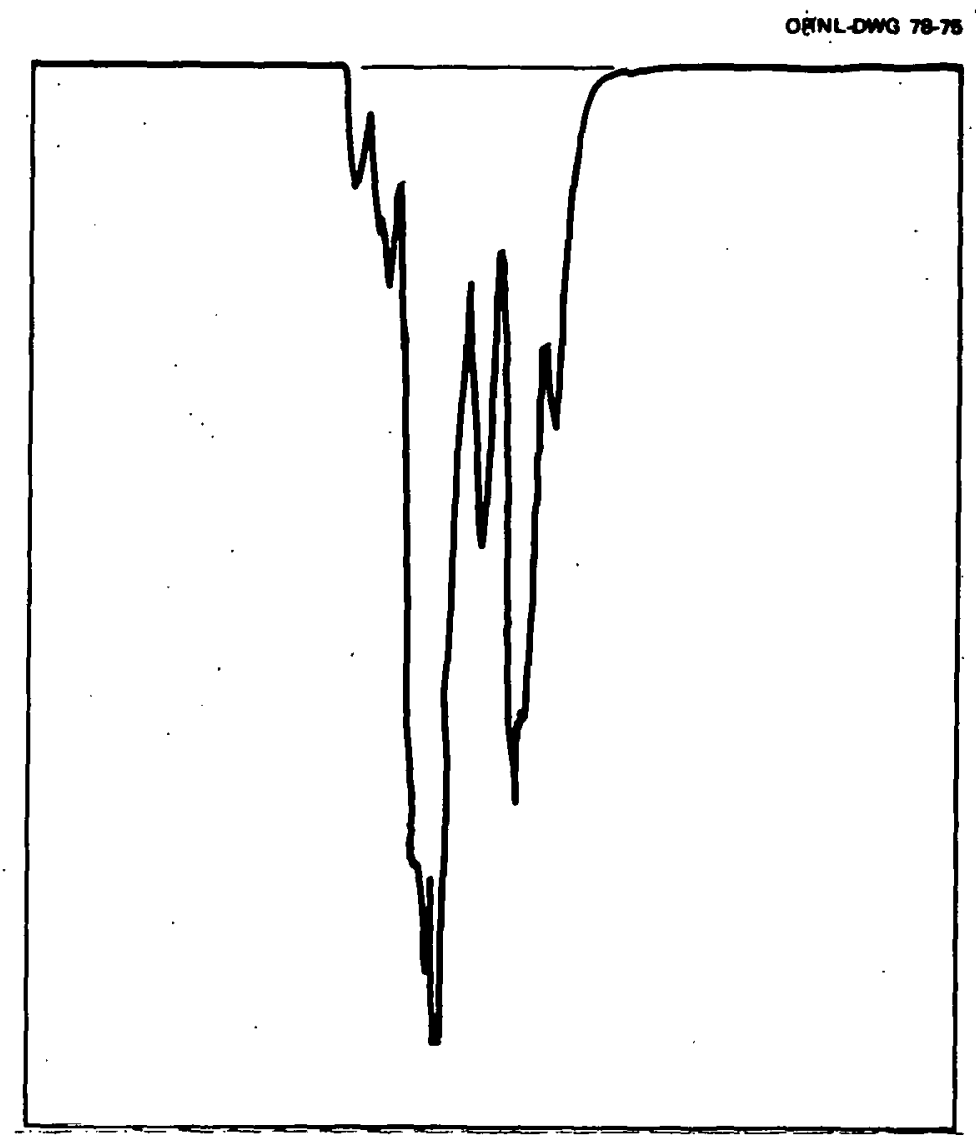

Fig. 7: Analog Recording of Arc Current vs Probe Position.

except for a check to ensure that the current variation did not cause the voltage across the $200-\Omega$ resistor to exceed the range of the logarithmic converter. The orientation of the plot results from the inverted output of the converter; zero voltage coincides with the top of the chart and the output is negative.

A number of single-line scans like Fig. 7 were made at intervals of $0.63 \mathrm{~mm}$ (0.025 in.) or $1.25 \mathrm{~mm}$ (0.050 in.) across the specimen. If one assumes that the location of the maximum arc current measurement correepondo to the location of the largest erack, then a crack map, as shown in Fig. 8, may be constructed. Figure 8 shows only the maximum values; the scans show smaller peaks as well, but their correlation becomes very complicated, and identification of continuous crack segments is uncertain. 


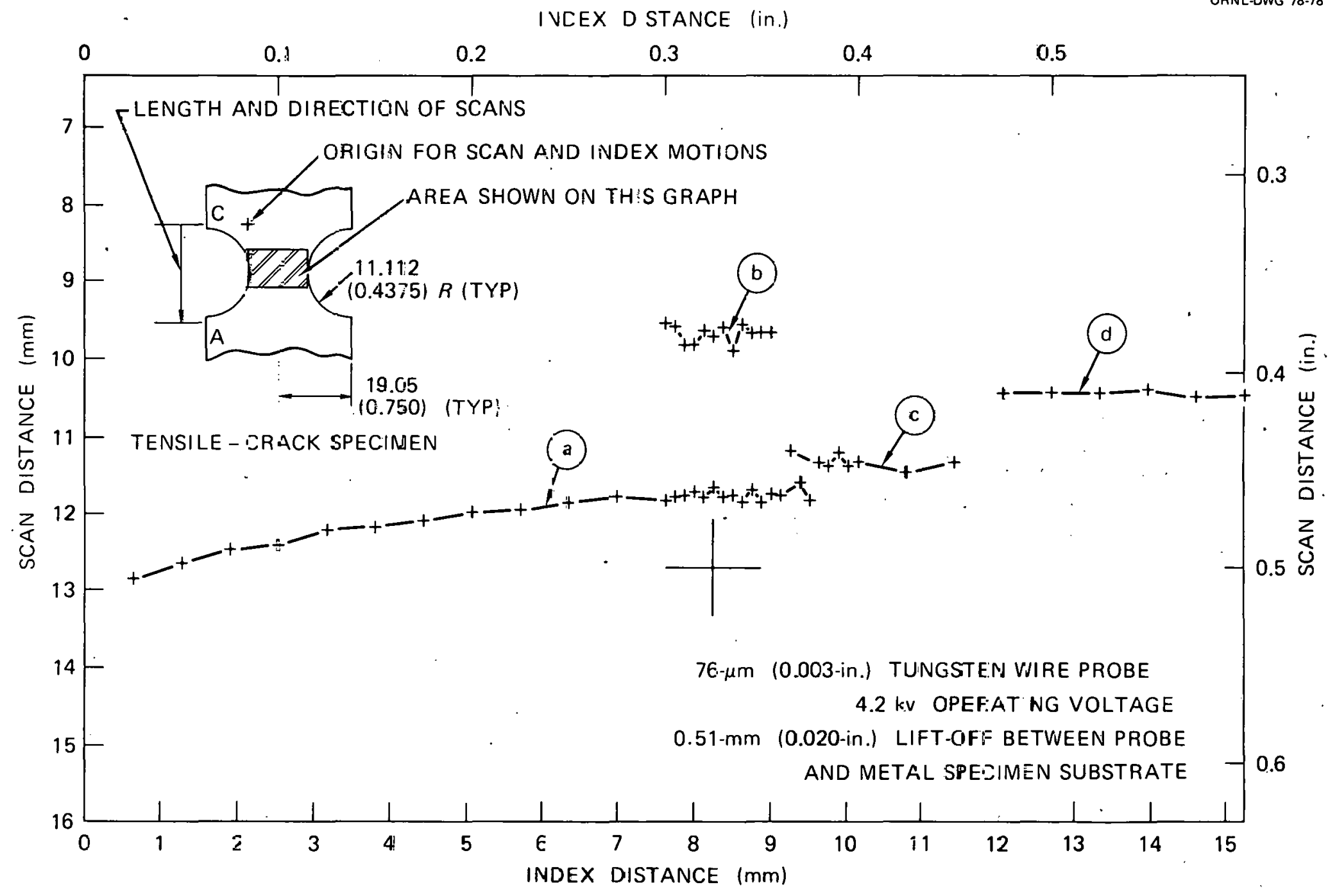

Fig. 8. Crack Map Constructed by Plotting the Location of Maximum Aro Current Measurements from Scans Like Fig. 7. 
We also examined the current amplitude variation along the major crack system. Figure 9 shows the amplitude of the arc current as a function of distance across the specimen (i.e., in the $Y$ direction). The higher current indications in Fig. 9 appear to correspond to the wider portions of the crack system, shown near the edges of the specimen in Fig. 5. This correspondence suggests a possible dependence of arc current on crack width. However; we have no information about the crack depth, for example, whether it penetrates completely through the specimen along its entire length, so depth may also be affecting the current..

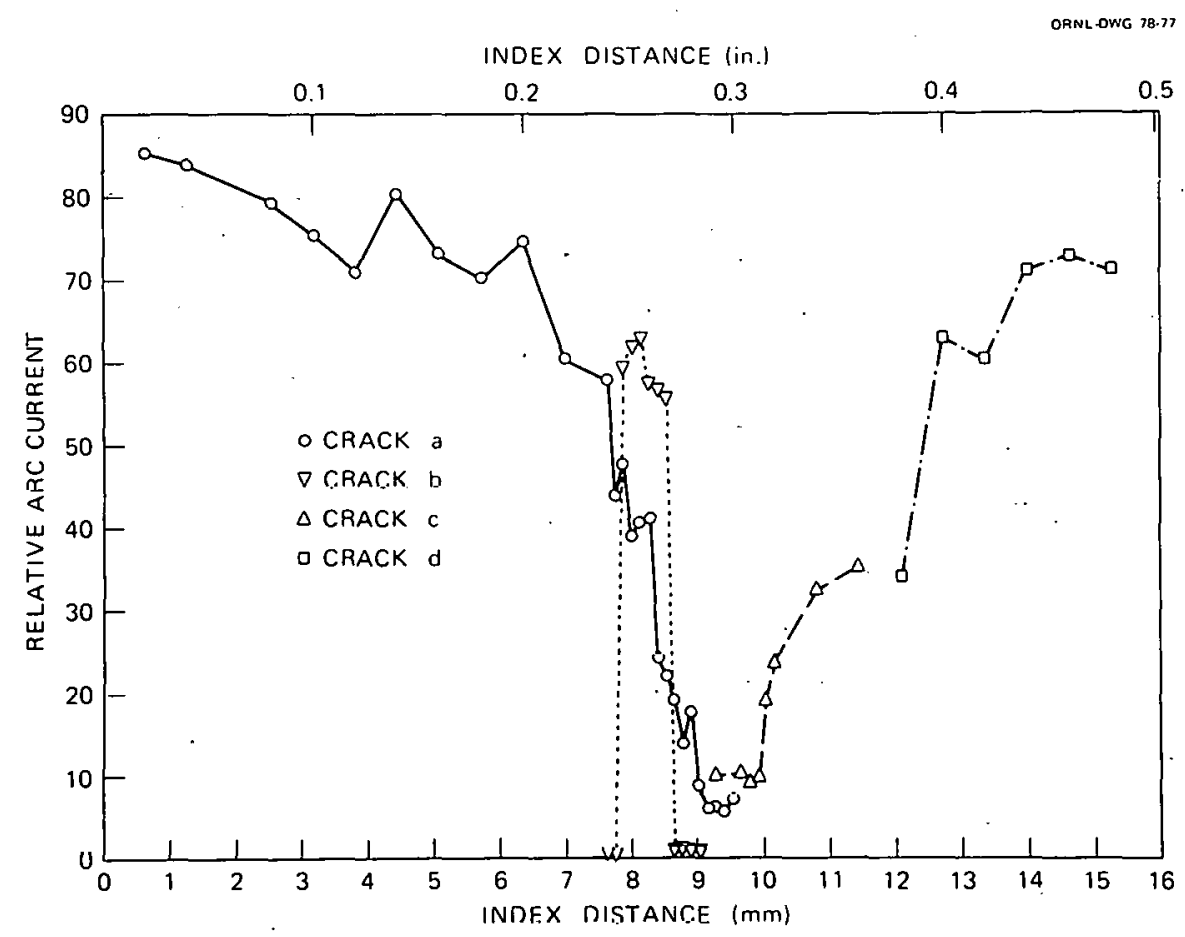

Fig. 9. Variation of Arc Current Along Segments of the Major Crack System. Identifying letter designations for the crack segments correspond to those in Fig. 8.

\section{Experimental Observations}

A number of effects were observed during the gathering of the analog data. Although some of these appear significant, most have not been pursued in detail because of the preliminary nature of the study. 
The arc tends to persist once it is struck:at a flaw site. If the location of a crack segment is visually correlated wh the Inception and extinction of the arc, we see that the extinction occurs at a point farther from the center of the crack than the inception does. The nature of the arc causes this; the ionized air column produced by the initial spark breakdown requires less field-strength to drive current across the gap. Persistence of the arc elongates the defect indications in the direction of probe motion. The exact amount of elongation has not been measured; it appears to add approximately $1.6 \mathrm{~mm}(0.06 \mathrm{in.})$ to the dimension of the indication (which is somewhat larger than llie actual crack). It would also introduce an error into any estimatés of flaw position based on measurements of the indicated pusilion. To get consigtent indications of defect positions for maps like Fig. 8, we needed to make all scans in the same direction.

Arc persistence may a1so mask defects. Resolution of a smaller crack "down-scan," that is, farther along the scan direction, from a larger crack may be prevented by at least two possible mechanisms. The arc to the larger crack may persist until the probe is well past the smaller crack before extinguishing, or the arc may jump from the larger crack to the smaller crack without a detectable interruption in current. In the second case, the smaller crack indication becomes part of the trailing edge of the larger 1ndlcatiun. Comparison of Figs. 5 and 7 yields some evidence of persistence. Figure 5 shows discrete, separated indications, while Fig. 7 shows one continuous indication with several local maxima and minima.

The $\mathrm{ZrO}_{2}$ coating contains small grains of free zirconium. This, according to the coating powder manufacturer, is a common occurrence in this type of coating. Zirconium is a much better conductor than $\mathrm{ZrO}_{2}$, so its effect would be to short out part of the resislatice and capacitance associated with the dielectric coating layer (see Fig. 1) and shorten the effective gap between the probe and the metal substrate. If a zirconium grain shorts uul enough of the probc-to-eubstrate gap, the resistance to the path can be reduced to that of an air gap and an arc will be produced. We observed a few isolated defect indications 
that did not have the shape of cracks. Although no hole or zirconium grain was visible at the site, large, subsurface grains could have produced the indications.

We observed some variation in arc current as repeated scans were made along the same line. The location of defect indications remained fixed within $0.2 \mathrm{~mm}$. We have not analyzed the data in sufficient detail to detect trends or estimate variation limits on either currents or defect locations.

\section{Plan View Recording}

We developed the plan view recorder to automate the construction of flaw maps like the one shown in Fig. 8. To substitute for the analog current measurement, we inserted the comparator with an adjustable reference, which converts the analog to binary. The recording obtained displays dimensional locations in a manner similar to that of the so-called "C-scan" recorder, which is frequently used in ultrasonic inspection.

We show four demonstration recordings (Figs. 10 and 11) made from the same area of the same specimen. Two arc current threshold settings are used, and positive- and negative-mode scans were made at each setting. The corner markings show the original $0.25 \times 0.38 \mathrm{~m}(10 \times 15$ in. $)$ chart size used; the outside scan lines indicate the width of the specimen throat, $16 \mathrm{~mm}$ (0.62 in.).

Figure 10(a) shows a positive image at the lower threshold. The threshold setting, $-50 \mathrm{~dB}$ on the logarithmic converter, corresponds to an arc current of approximately $160 \mu \mathrm{A}$. The image of one large, nearly continuous defect area indicates poor resolution, of which the causes have not been explored in detail. Some of the effects discussed above are likely causes.

Figure $10(\mathrm{~b})$ shows a negative image scan at the same settings as Fig. 10(a). Again, the continuous image indicates poor resolution. although the separation of parts of the image is somewhat greater and easier to observe. Defect size in the scan direction is slightly smaller on the negative image, possibly indicating a hysteresis effect in the 


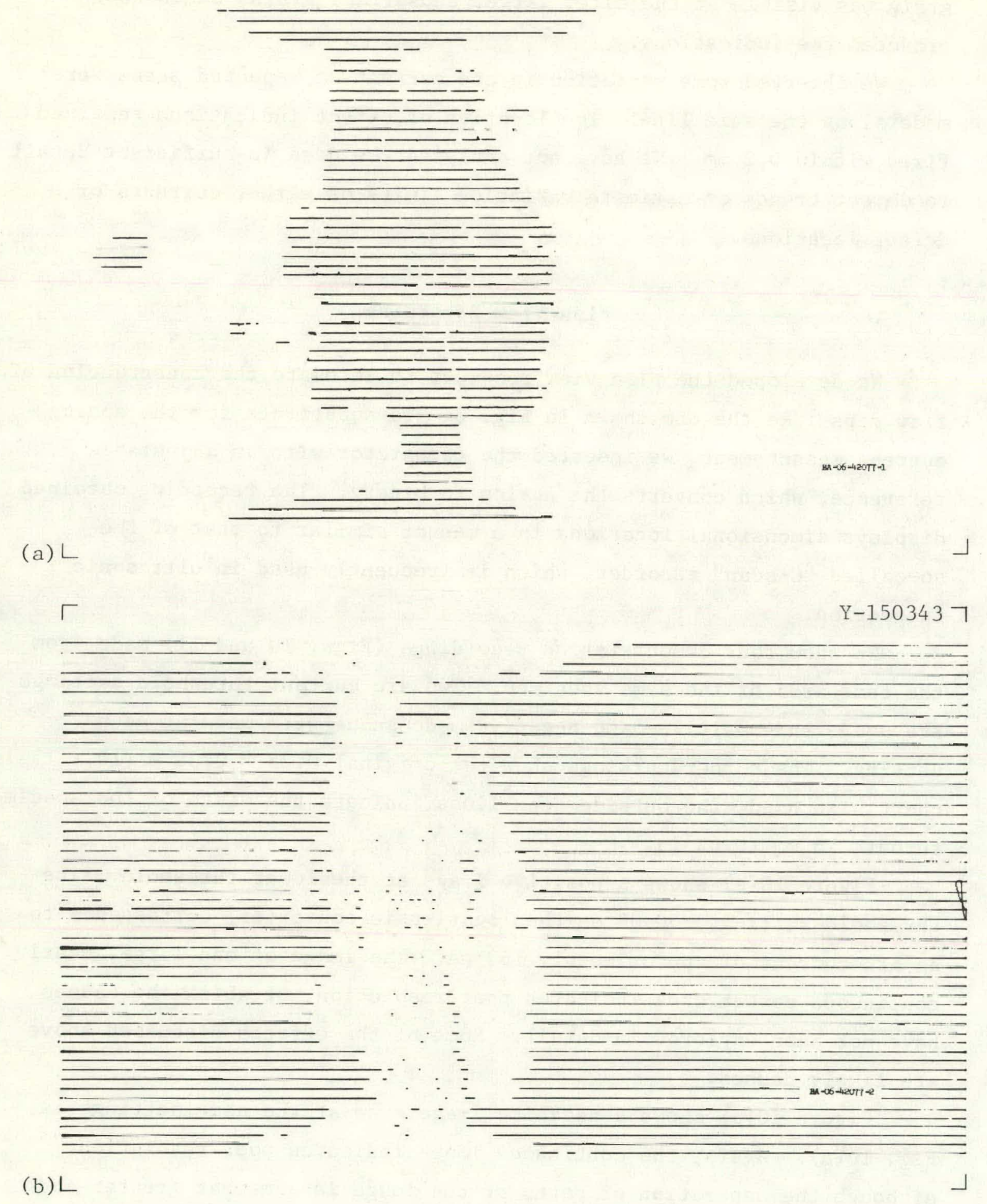

Fig. 10. Plan View Recordings of Arc Test Defect Indications at -50 dB Threshold (Arc Current $160 \mu \mathrm{A}$ ). (a) Positive image. (b) Negative image. 


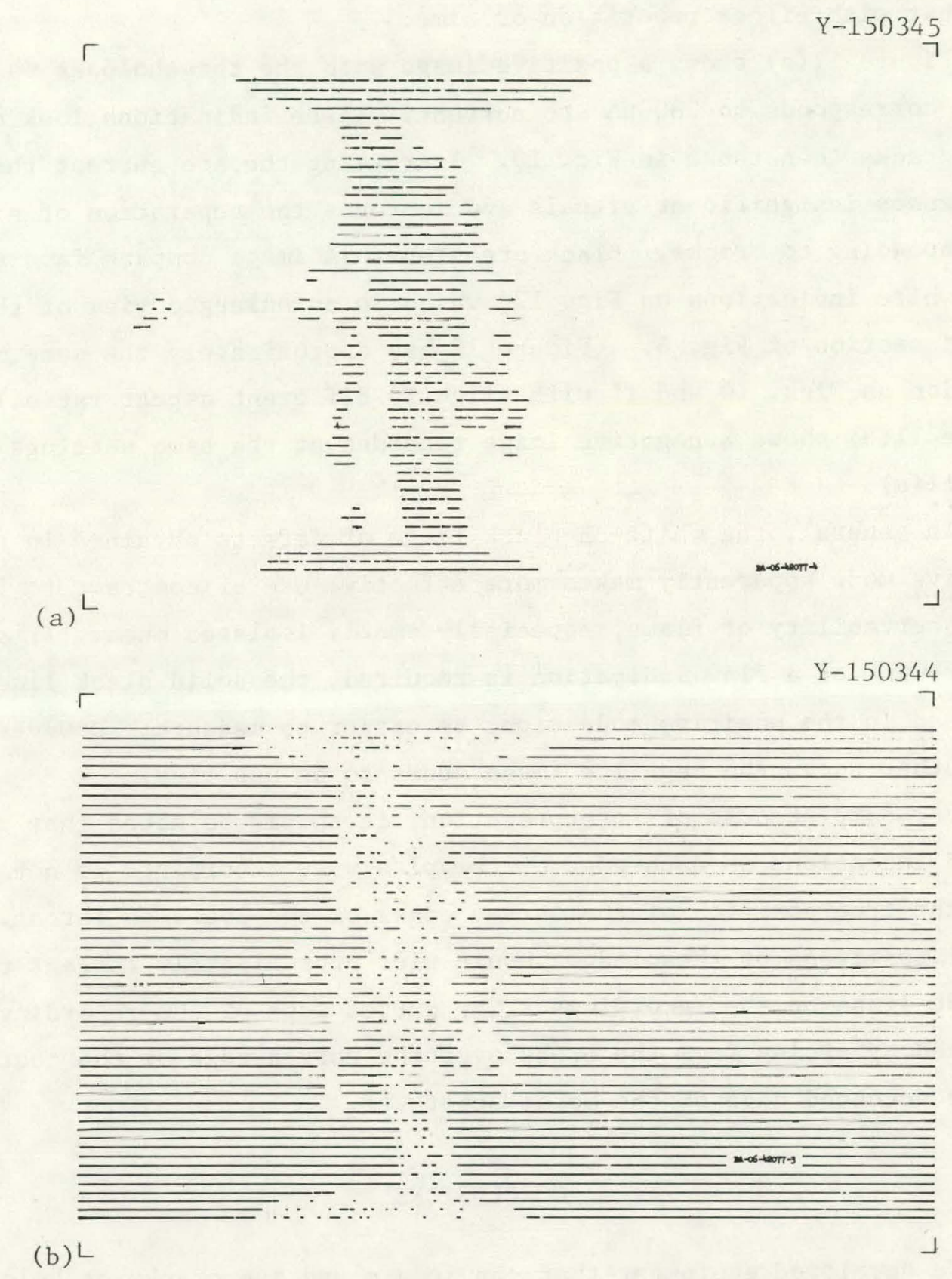

Fig. 11. Plan View Recordings of Arc Test Defect Indications at $-45 \mathrm{~dB}$ Threshold (Arc Current $280 \mu \mathrm{A}$ ). (a) Positive image. (b) Negative image. 
relay system that controls the pen position. (Scan speed was the same for each image.) As noted above, the system response also changes somewhat with either repetition or time.

Figure 11 (a) shows a positive image with the threshold at $-45 \mathrm{~dB}$, which corresponds to $280 \mu \mathrm{A}$ arc current. These indications look more like cracks than those in Fig. 10. Increasing the arc current threshold suppresses insignificant signals and improves the separation of signals corresponding to cracks. Black areas on this image compare favorably with white indications on Fig. 12, which is an enlarged view of the center section of Fig. 6. (Figure 12 has approximately the same magnification as Figs. 10 and 11 with slightly different aspect ratio.) Figure $11(b)$ shows a negative image recorded at the same settings as Fig. 11(a).

In genera1, the white-on-black image of defects obtained in the negative mode apparently makes more effective use of contrast to improve the observability of flaws, especially small, isolated ones. If a size measurement of a flaw indication is required, the solid black line obtained in the positive mode might be easier to measure. However, for most other uses, the negative image seems to be superior.

For completeness of interpretation, it should be noted that the curved indentions on each edge of the plan view recordings do not represent the true position of the curved edges of the specimen throat. The actual positions of these edges would plot approximately tangent to the outside lines on the recordings. The curved edge of the recording is produced by arcing from the probe over the curved edge of the coating to the uncoated edge of the metal substrate.

\section{CONCLUSIONS}

We developed equipment that can locate and map cracks or holes in ceramic coatings. A flaw is detected by the formation of an arc discharge between a scanning high-voltage probe and the metal substrate underlying the coating. Key features of the equipment include: (1) logarithmic amplification of the arc current measuring signal and (2) an adjustable arc current threshold for actuation of the recording system. 


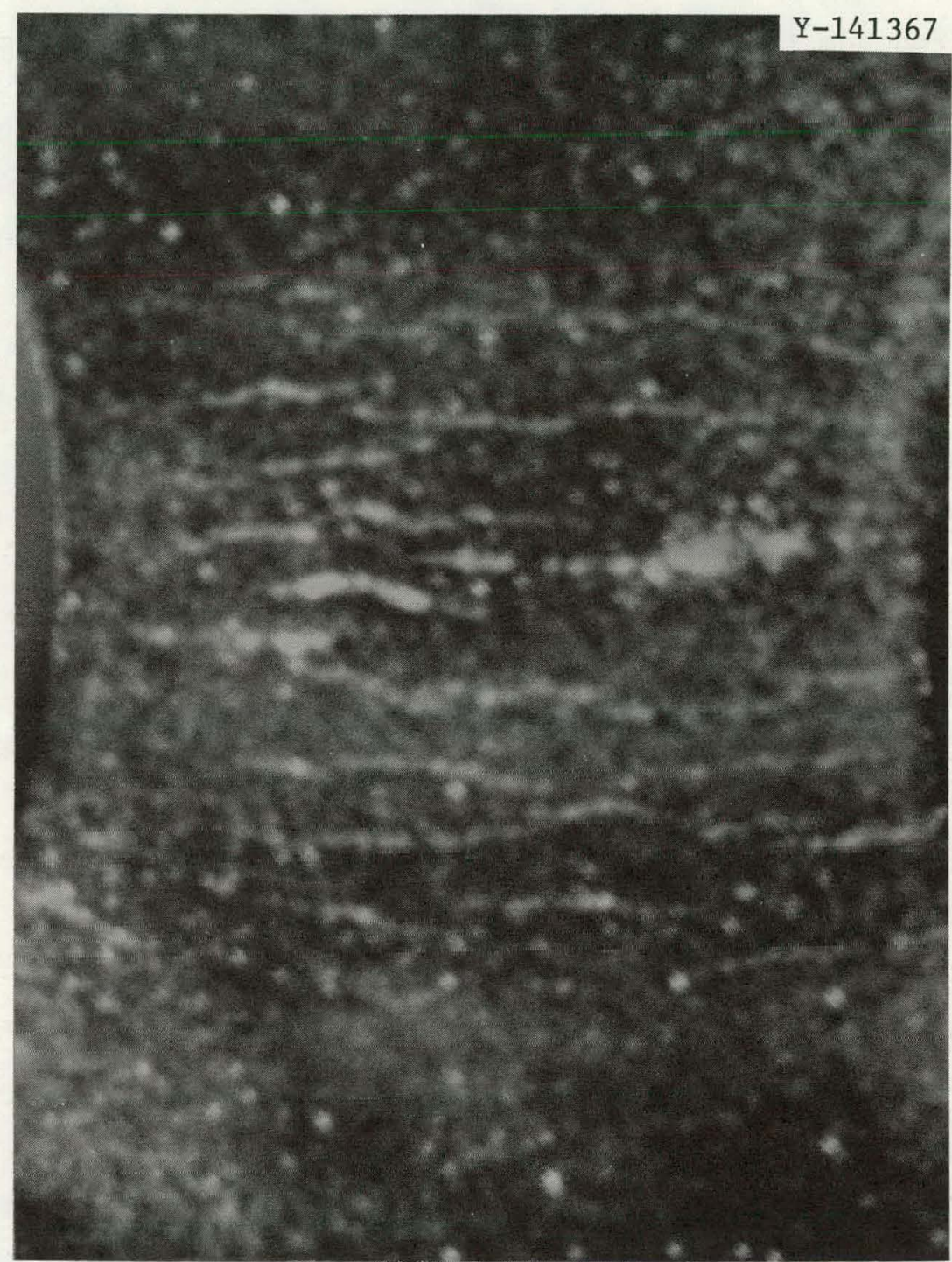

Fig. 12. Enlarged View Showing Filtered Particle Indications in Area of Specimen Corresponding to Plan-View Recordings, Figs, 10 and 11 (6x enlargment of Fig. 6). 
Logarithmic current amplification enhances the selectivity and resolution of the system by allowing it to respond to the wide range of current levels that occur during electrical breakdowns and discharges. The linear range required would probably not be available in suitable amplifiers.

The adjustable arc current threshold provides a sensitivity correction, which improves resolution. Although a relation between physical flaw dimensions and arc current has not been established, the observations indicate that current increases with flaw size. Therefore, the arc current threshold provides some sorting action to different1ate flaws by the arc current they pass. Proper choice of threshold level produces flaw maps that closely resemble visual indications produced by surface inspection techniques.

Experimental observations provide some clues about the general behavior of discharge phenomena in the inspection situation: smaller gaps between probe and substrate produce more concentrated fields and improve resolution. Differences in defect structures cause reproducible differences in the arc current response. These differences have been partially identified, but their effects cannot be completely differentiated at this time.

\section{Applications}

Similar arc-discharge methods should be useful for the detection of flaws in any insulating material layer on metal if the layer would not be damaged by the passage of an arc through an open flaw to the metal substrate. Features of the prototype system described here can be applied to any inspection task performed with existing "whisk-broom" probe holiday detectors. $\Lambda$ single-puinl hand-held probe with controlled lift-off would be useful to localize and mark flaws initially detected by a whisk-broom inspection if repair were planned. The recording tcchnique shown here could he adapted to field use where a permanent record of the defect pattern is needed. 


\section{Future Work}

Objectives of the program that supported this work do not currently Justify further development efforts, since feasibility has been shown, However, a number of improvements could be considered. Tracking the substrate location with another type probe, such as eddy current, would allow voltage control to assure a constant field across the probe-substrate gap. Voltage cut-off or pulse techniques to minimize arc persistence would improve resolution. Rapid-response instrumentation would allow faster mechanical scanning. The next level of research effort could include studies of the discharge phenomena and examination of the low-current discharge regime preceding the arc for applications to flaw detection:

\section{ACKNOWLEDGMENTS}

S. D. Snyder's development of the tensile-crack specimen, although intended for other purposes, contributed significantly to this work. C. Ruffner built the Scan and Recording Controller; H. T. Murrin and J. D. Hudson prepared the specimen. Arvid E. Pasto and Laszlo Adler reviewed the manuscript. Sigfred Peterson edited the report, and Kathryn Witherspoon prepared the reproducible copy. 
THIS PAGE

\section{WAS INTENTIONALLY \\ LEFT BLANK}


APPENDIX

SCAN AND RECORDING CONTROLLER 
THIS PAGE

\section{WAS INTENTIONALLY}

LEFT BLANK 
SCAN AND RECORDING CONTROLLER

Functions

The unit was designed to perform the following functions:

1. isolate $X$ - and $Y$-axis position data potentiometers from the $X-Y$ recorder system, to avoid loading the data potentiometer;

2. control and provide adjustment of $X$ and $Y$ magnification and the aspect ratio ( $X$-maynification/ $Y$-magnification) of the recordings;

3. provide constant-voltage power to the $X$ - and $Y$-axis data potentiometers;

4. convert the analog signal from the logarithmic converter to a binary output for pen position (up/down) control (conversion includes an adjustable reference threshold voltage).

Circuit Description and Operation - See Fig. A1

$\underline{X-\text { and } Y \text {-axis Position }}$

The signal from the wiper of the $X$ data potentiometer feeds through the $X-Y$ Position In jack to IC- 1 . The $X$-Mag Selector, $S_{1}$, selects a fixed gain of $1,2,3,4$, or 5 by controlling the feedback of IC- 1 . The Direct Scan $X$ output provides a terminal for measuring the $X$ data potentiometer voltage with an external meter, which is useful in resetting an earlier probe position.

The $Y$-axis position signal circuitry is identical to that for the $X$-axis, except the feedback resistors attached to the $Y$-Mag control (s3) provide magnifications of 1,2 , and 4 only.

\section{Data potentiometer power}

Potentiometers $\mathrm{R} 12$ and $\mathrm{R} 13$ act as voltage dividers to provide continuously adjustable voltages, $0-15 \mathrm{~V}$ dc, to the $X$ and $Y$ data potentiometers, respectively. Combined with the $X$ and $Y$ magnification controls, $R 12$ and R13 provide continuously adjustable magnifications. 


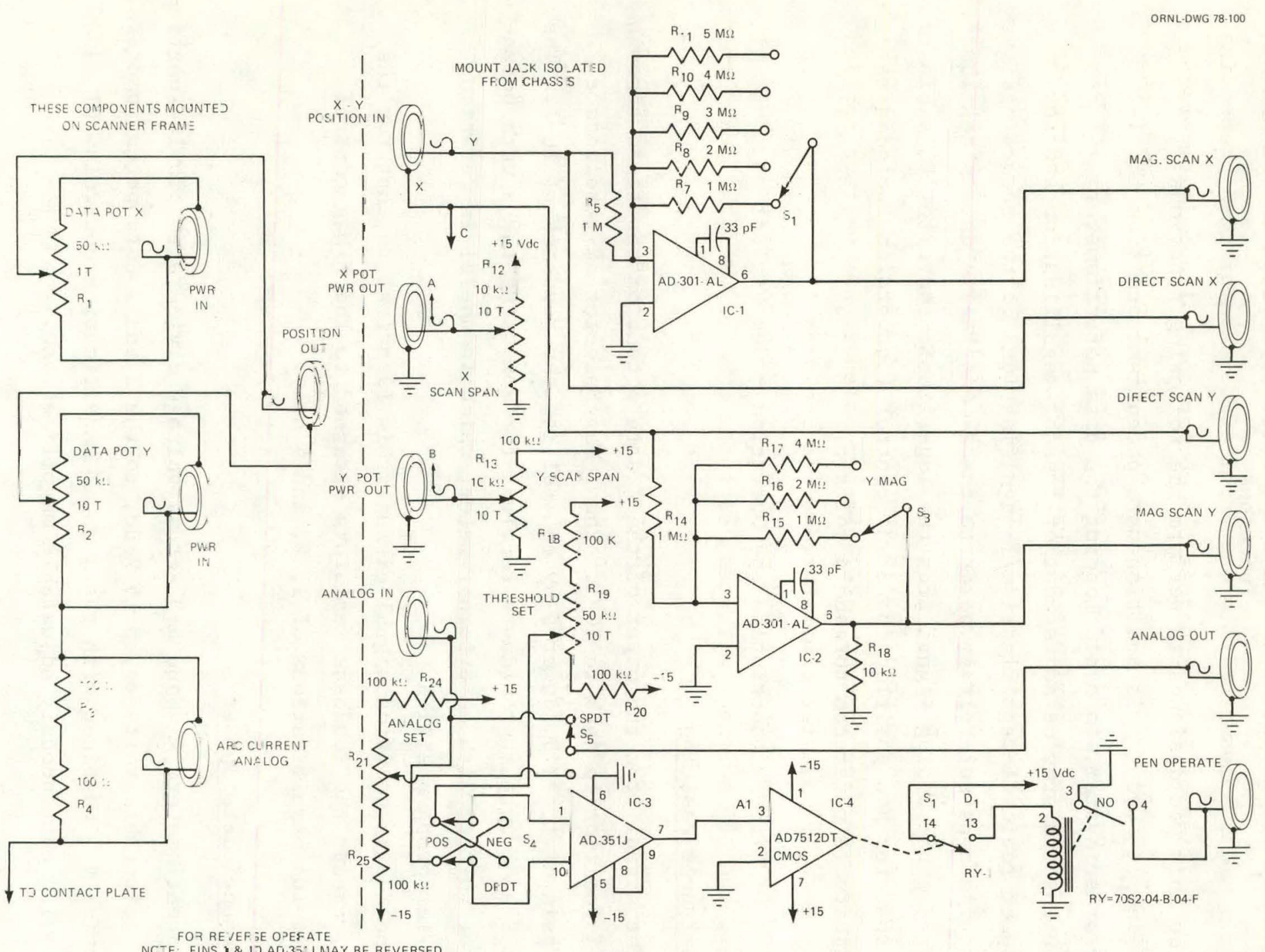

Fig. Al. Llectrical Schematic of the Scan and Recording Controller, Including Data Potentiometers Mounted on the Scanning Mechanism. 


\section{Pen control}

The output of the logarithmic converter is applied to the Analog In jack, which transmits it to one input of comparator IC-3, depending on the position of $\mathrm{S4}$. An adjustable comparison voltage is generated across $\mathrm{R} 18-\mathrm{R} 19-\mathrm{R} 20$ and applied to the other input of IC-3. When the voltage at terminal 1 of IC-3 is greater than the voltage at terminal 10, IC-3 generates a positive dc output (for $V_{10}>V_{1}$, IC-3 output is zero). A positive voltage applied to terminal 3 of CMOS switch IC-4 causes its normally open path to close, energizing $\mathrm{R} 1$ and closing contracts 3 and 4 .

The recorder pen position is controlled by a solenoid (not shown). In the External Pen Control mode, the pen solenoid has voltage applied to one terminal and the other terminal is isolated from ground, so no current flows and the pen stays up (i.e., it does not write). When Rl closes, the pen solenoid actuates, dropping the pen, and the pen commences commences writing.

The Analog Set control R21-R24-R25 provides signals for checking IC-3 and an external output, which can be fed to the log converter to set up the threshold voltages. 
THIS PAGE

\section{WAS INTENTIONALLY LEFT BLANK}


ORNL/TM-6176

INTERNAL DISTRIBUTION

1-2. Central Research Library

3. Document Reference Section

4-6. Laboratory Records Department

7. Laboratory Records, ORNL RC

8. ORNL Patent Office

9. M. Bender

10. N. K. Bernander $(\mathrm{Y}-12)$

11. H. D. Cochran, Jr.

12. K. V. Cook

13. K. E. Cowser

14. E. V. Davis

15. V. A. DeCar1o

16. C. V. Dodd.

17. - W. P. Eatherly

18. D. P. Edmonds

19. D. E. Ferguson

20. L. M. Ferris

21. B. E. Foster

22. W. Fulkerson

23. J. W. Garber $(\mathrm{K}-25)$

24. T. G. Godfrey

25. G. M. Goodwin

26. R. J. Gray

27. W. L. Greenstreet

28. J. R. Hightower

29-31. M. R. Hill

32. R. S. Holcomb

33. J. M. Holmes

34.. J. K. Huffstetler

35. V. C. Jackson ( $Y-12)$

36. G. K. Jasny $(Y-12)$

37. J. E. Jones, Jr.

38. R. T. King

39. W. J. Lackey

40. W. R. Laing

41. J. S. Lin

42. R. S. Livingston

43. P. L. Long (Y-12)

44. R. E. MacPherson
45. W. R. Martin (Y-12)

46. D. L. Mason $(Y-12)$

47. W. J. Mason

48. R. W. McClung

49. R. F. McDonald

50. J. R. McGuffey

51. L. E. McNeese

52. J. R. McWherter

53. H. J. Metz

54. C. S. Morgan

55. F. D. Mundt $(\mathrm{K}-25)$

56. J. P. Nichols

57. L. C. Oakes

58. T. W. Pickel

59. H. Postma

60. C. R. Richmond

61. M. W. Rosenthal

62. T. H. Row

63. R. Salmon

64. G. Samuels

65. C. D. Scott

66-70. G. W. Scott

71. W. A. Simpson, Jr.

72. G. M. Slaughter

73. J. H. Smith

74. R. F. Smith (K-25)

75. S. D. Snyder

76. I. Spiewak

77. V. J. Tennery

78. H. E. Tramme11

79. D. B. Trauger

80. G. D. Whitman

81. L. .V. Wilson

82. C. S. Yust

83. L. Adler (Consultant)

84. S. Alpert (Consultant)

85. H. Beuther (Cnnsultant)

86. M. Semchyshen (Consultant)

87. H. W. Sternberg (Consultint)

88. C. Streed (Consultant) 
EXTERNAL DISTRIBUTION

89. Ames Laboratory, 205 Met. Dev. Bldg. Iowa State University, Ames, IA 50011

T. E. Scott

90. Argonne National Laboratory, 9700 S. Cass Avenue, Argonne, IL 60439

o. K. Chopra

Steven Danyluk

W. A. Ellingson

K. Natesan

J. Y. Park

W. J. Shack

D. Stah1.

R. Swaroop

91. Babcock \& Wilcox Company, P. 0. Box 1260, Lynchburg, VA 24505

E. M. Anderson

92. Battelle Columbus Laboratories, $505 \mathrm{King}$ Avenue, Columbus, OH 43201
A. M. Hall
J. J. Mueller
J. R. Schorr
I. G. Wright

93. Battelle Pacific Northwest Laboratory, P. O: Box 999, Richland, WA 99352

\section{J. J. Bates}

94. Cabot Corporation, Stellite Division, 1020 Park Avenue, Kokomo, IN 46901

R. B. Herchenroeder

95. Combustion Engineering, Inc., 1000 Prospect Hill Road, Windsor, CT 06095
A. L. Plumley

96. Combustion Engineering Power Systems, 911 West Main Street, Chattanooga, TN 37402

E. C. Lewis

97. Electr1c Power Research Institute, 3412 Hillview Ave., Palo Alto, CA 94304

F. L. Culler

R. I. Jaffee

I. Stringer 
98. Exxon Research and Engineering Company, P. O. Box 51, Linden, NJ 07036

M. S. Nutkis

99. Fluidyne Engineering Corp., P. 0. Box Drawer 1465, Springfield, VA 22151

L. R. White

100. Foster Wheeler Development Corporation, 12 Peach Tree Hill Road, Livingston, NJ 07039

I. M. Rehn

101. Genera1 Electric Company, 1 River Road, Schenectady, NY 12019

M. B. Cutrone

H. V. Doering

R. M. Goldhof $f$

R. L. McCarron

102. International Nickel Company, Sterling Forest, Suffern, NY 10901

E. P. Sadowski

103. Lockheed Palo Alto Research Laboratories, 3251 Hanover Street, Palo Alto, CA 94304

R. A. Perkins

104. Metal Properties Council, Inc., 1351 Butler Pike, Blue Bel1, PA 19422

A. 0. Schaefer

105. Nationa1 Bureau of Standards, Washington, DC 20234

J. H. Smith

106. Pratt \& Whitney Aircraft, Aircraft Road, Middletown; CT 06457

T. S. Pettit

107. Sandia Laboratories, Livermore, CA 94550

R. Bradshaw

108. Solar Turbines International, 2200 Pacific Highway, P. O. Box 80966, San Diego, CA 92122
A. G. Metcalfe

M. E. Ward

109. University of Notre Dame, Box E, Met. Eng. and Materials Science, Notre Dame, IN 46556

N. F. Fiore

110. U. S. Bureau of Mines, P. O. Box 70, Albany, OR 97321

F. W. Wood 
111. Westinghouse Electric Corporation, 1310 Beulah, Pittsburg, PA 15235

R. J. Bratton

T. J. Harvey

J. D. Landes

D. Moon

T. Vofnovich

112. DOE, Office of Fossil Energy, 20 Massachusetts Avenue, N.W., Washington, DC 20545

W. T. Bakker

John Falrbanks

H. E. Franke1

113. DOE, Oak Ridgc Operations Uffise, P: O. Rnx F, nak Ridge. TN 37830

Research and Technical Support Division

114-140. DOE, Technical Information Center, Office of Information Services, P. O. Box 62, Oak Ridge, TN 37830

\&U.S. GOVERNMENT PRINTING OFFICE: $1978-740-190 / 6$ 